\title{
Autoimmune hemolytic anemia associated with infliximab infusion in ulcerative colitis
}

\author{
Fazia A. Mir, Alhareth Al Juboori, Jack D. Bragg, Veysel Tahan \\ Department of Gastroenterology and Hepatology, Missouri University, Columbia, Missouri, USA
}

\begin{abstract}
Infliximab is a monoclonal antibody that antagonizes the activity of tumor necrosis factor alpha to induce and maintain remission in patients with inflammatory bowel disease. Adverse effects associated with Infliximab infusions include infusion reactions, risk of infections, development of hematological malignancies, and pancytopenia. Autoimmune hemolytic anemia has rarely been reported in ulcerative colitis. Herein we report a case of drug-induced hemolytic anemia after infliximab infusion for treating ulcerative colitis.
\end{abstract}

Keywords: Autoimmune hemolytic anemia; inflammatory bowel disease; infliximab; ulcerative colitis.

$\mathrm{T}$ umor necrosis factor alpha (TNF-a) is a proinflammatory cytokine found in increased concentrations in the blood, colonic tissue, and stools of patients with inflammatory bowel disease including Crohn's disease and ulcerative colitis (UC) [1]. Infliximab is a monoclonal antibody that antagonizes the activity of TNF-a to induce and maintain remission in patients with inflammatory bowel disease. Adverse effects associated with infliximab infusions include infusion reactions, risk of infections, and the development of lymphoma [2].

Herein we discuss the case of a patient with autoimmune hemolytic anemia (AIHA) receiving infliximab infusion for the treatment of UC.

\section{CASE REPORT}

A 42-year-old male with a history of pancolonic UC diagnosed in 2009 with no response to mesalamine, azathioprine, and prednisone presented to a university clinic to receive care. Colonoscopy performed in 2014 showed pancolitis, diffuse erythema, and ulceration. At that time, the patient also had clinically significant symptoms with 10 diarrheal bowel movements a day. The patient was started on $5 \mathrm{mg} / \mathrm{kg}$ infliximab every 8 weeks after colonoscopy with concomitant $10 \mathrm{mg}$ prednisone daily for functional treating adrenal insufficiency that developed due to prolonged steroid use. 
At the 6-month follow-up, the patient reported significant improvement in his diarrheal symptoms and reduction in his bowel movement frequency. A decision was made to continue with infliximab with close followup care.

At a routine 2-month follow-up visit after being on infliximab for a year, the patient reported extreme fatigue, while denying the presence of blood in his stool or urine. A physical examination showed conjunctival pallor and scleral icterus. His complete blood count and chemistry panel were indicative of pancytopenia, with a hemoglobin level of $5.7 \mathrm{~g} / \mathrm{dL}$ (baseline $14 \mathrm{~g} / \mathrm{dL}$ ), white blood cell count of $1550 / \mathrm{mcL}$, platelet count of $121000 / \mathrm{mcL}$, total bilirubin level of $2.88 \mathrm{mg} / \mathrm{dL}$, and direct bilirubin level of $0.6 \mathrm{mg} / \mathrm{dL}$. His peripheral smear showed macrocytosis, anisocytosis, poikilocytosis, tear drop cells, and spherocytosis. The patient was then referred to the Hematology Department for undergoing a further evaluation. His direct Coombs test result was positive.

Given the findings of his direct Coombs test, AIHA was diagnosed, and it was concluded that his anemia was secondary to drug-induced hemolysis from infliximab infusion. A decision was made to discontinue infliximab treatment and monitor serial hemoglobin levels and hematocrit. In his follow-up visit, his hemoglobin levels improved to $13.2 \mathrm{~g} / \mathrm{dL}$. He was then started on vedolizumab as a maintenance biologic for his UC.

\section{DISCUSSION}

AIHA is a blood disorder in which immunoglobulin $\mathrm{G}$ and/or immunoglobulin $\mathrm{M}$ attach to red cell surface antigens and start red cell destruction by activating the complement system and the reticuloendothelial system [3]. Immune hemolytic anemia is classified as either autoimmune, alloimmune, or drug induced depending on the immunological response triggered by antigen stimulation [3]. Drug-induced antibodies can recognize either intrinsic red cell antigens or red cell-bound drugs, and antibodies that react with the red cell-bound drug require the drug for hemolysis [4]. A presumptive diagnosis can be made only if patients respond to withdrawal of the drug, as was witnessed in our patient.

AIHA can occur in patients with UC. It can simultaneously present with a flare-up of UC but remits with control of the disease $[5,6]$.

Drug-induced hemolytic anemia has been well documented with high dose penicillin, methyldopa, and certain third-generation cephalosporins [2]. There have been three cases of AIHA reported in the literature to be caused by infliximab [7-9]. In a study conducted by Vermeire et al. who investigated the occurrence of antinuclear antibodies in 125 consecutive Crohn's disease patients, it was noted that one patient had developed sudden-onset anemia with icterus and was diagnosed with Coombs negative AIHA 6 months after the first infusion [7]. In this study, the prevalence of hemolytic anemia in patients with infliximab infusion was $0.8 \%$ at the follow-up. A study conducted by Fidder et al. evaluated the long-term safety of infliximab by reviewing the records of $734 \mathrm{pa}-$ tients treated with the drug and showed that one patient developed Coombs negative AIHA 6 months after the single administration of infliximab [8]. Vermerie et al. identified predictive factors of the response to infliximab and noted that three patients developed hematological problems, with one patient developing AIHA [9].

Leo-Carnerero et al. presented two interesting cases of UC with documented severe anemia secondary to AIHA that responded well to infliximab treatment in both conditions. Their 26-year-old female patient had left-sided colitis and 35-year old female patient had pancolitis. Infliximab treatment improved not only colitis but also AIHA after the second induction dose in both patients. In the absence of data supportive to their findings, they speculated that depending on the physiopathology, if AIHA develops as a result of the cross-reactivity of erythrocytes and autoantibodies against antigens in the colon, such UC patients with AIHA can improve in both conditions with infliximab treatment $[10,11]$. In our case, the patient did not have anemia before treatment and AIHA developed after infliximab treatment, similar to the previous three cases in the literature [7-9].

It is important to closely follow-up patients on infliximab treatment and withdraw the biologic when side effects arise. Despite the limited number of patients with hemolytic anemia secondary to infliximab infusion, providers need to be aware of such adverse effects of therapy an increasing number of patients are started on infliximab for treating inflammatory bowel disease.

Conflict of Interest: No conflict of interest was declared by the authors.

Financial Disclosure: The authors declared that this study has received no financial support.

Authorship contributions: Concept - F.A.M., A.A.J., J.D.B., V.T.; Design - F.A.M., A.A.J., J.D.B., V.T.; Supervision - J.D.B., V.T.; Materials - F.A.M., A.A.J., J.D.B., V.T.; Data collection \&/or processing - F.A.M., A.A.J., J.D.B., V.T.; Analysis and/or interpretation - F.A.M., A.A.J., J.D.B., V.T.; Writing - F.A.M., A.A.J., J.D.B., V.T.; Critical review - J.D.B., V.T. 


\section{REFERENCES}

1. Rutgeerts P, Sandborn WJ, Feagan BG, Reinisch W, Olson A, Johanns $\mathrm{J}$, et al. Infliximab for induction and maintenance therapy for ulcerative colitis. N Engl J Med 2005;353:2462-76. [CrossRef]

2. Aronson JK. Meyler's Side Effects of Analgesics and Anti-inflammatory Drugs. 1st ed. Elsevier; 2009.

3. Chaudhary RK, Das SS. Autoimmune hemolytic anemia: From lab to bedside. Asian J Transfus Sci 2014;8:5-12. [CrossRef]

4. Gehrs BC, Friedberg RC. Autoimmune hemolytic anemia. Am J Hematol 2002;69:258-71. [CrossRef]

5. Leo Carnerero E, Aouf S, Montero Cuadrado I, Herrera Martin P, Herrera Justiniano JM. Autoimmune hemolytic anemia associated with ulcerative colitis: response to infliximab. Am J Gastroenterol 2009;104:2370-1. [CrossRef]

6. Molnár T, Farkas K, Szepes Z, Nagy F, Wittmann T. Autoimmune hemolytic anemia associated with ulcerative colitis: the most important step is to induce complete remission. Am J Gastroenterol 2010;105:1203-4. [CrossRef]
7. Vermeire S, Noman M, Van Assche G, Baert F, Van Steen K, Esters N, et al. Autoimmunity associated with anti-tumor necrosis factor alpha treatment in Crohn's disease: a prospective cohort study. Gastroenterology 2003;125:32-9. [CrossRef]

8. Fidder H, Schnitzler F, Ferrante M, Noman M, Katsanos K, Segaert S, et al. Long-term safety of infliximab for the treatment of inflammatory bowel disease: a single-centre cohort study. Gut 2009;58:501-8. [CrossRef]

9. Vermeire S, Louis E, Carbonez A, Van Assche G, Noman M, Belaiche $\mathrm{J}$, et al. Demographic and clinical parameters influencing the short-term outcome of anti-tumor necrosis factor (infliximab) treatment in Crohn's disease. Am J Gastroenterol 2002;97:2357-63. [CrossRef]

10. Leo Carnerero E, Aoufi S, Montero Cuadrado I, Herrera Martin P, Herrera Justiniano JM. Autoimmune hemolytic anemia associated with ulcerative colitis: response to infliximab. Am J Gastroenterol 2009;104:2370-1. [CrossRef]

11. Leo-Carnerero E, Araujo-Míguez A, Trigo-Salado C, De-la-CruzRamírez MD, Herrera-Justiniano JM, Márquez-Galán JL. The effect of controlling inflammatory activity in the colon on the response to infliximab of autoimmune haemolytic anaemia associated with ulcerative colitis. Rev Esp Enferm Dig 2014;106:295-6. 